Pesq. Vet. Bras. 38(5):935-948, maio 2018

\title{
Doenças do sistema nervoso central em cães ${ }^{1}$
}

\author{
Maria T.S. Frade ${ }^{2 *}$, Jefferson S. Ferreira ${ }^{2}$, Maria J.R. Nascimento ${ }^{3}$, \\ Vitória V.F. Aquino ${ }^{3}$, Isabel L. Macêdo ${ }^{3}$, Rosileide S. Carneiro ${ }^{4}$, Almir P. Souza ${ }^{5}$ \\ e Antônio F.M. Dantas ${ }^{5}$
}

\begin{abstract}
Frade M.T.S., Ferreira J.S., Nascimento M.J.R., Aquino V.V.F., Macedo I.L., Carneiro R.S., Souza A.P. \& Dantas A.F.M. 2018. [Central nervous system disorders diagnosed in dogs.] Doenças do sistema nervoso central em cães. Pesquisa Veterinária Brasileira 38(5):935-948. Laboratório de Patologia Animal, Hospital Veterinário, Centro de Saúde e Tecnologia Rural, Universidade Federal de Campina Grande, Campus de Patos, Av. Universitária s/n, Bairro Santa Cecília, Patos, PB 58708-110, Brazil. E-mail: talita frade@hotmail.com

Central nervous system (CNS) diseases in dogs diagnosed in the backlands of Paraiba are described. The necropsy records of 1,205 of dogs were reviewed. In 354 cases (29.38\%) a history of clinical alterations of the nervous system were recorded. Two hundred and ninety six cases had a definitive diagnosis and 58 were inconclusive. Infectious diseases were observed in $59.60 \%(211 / 354)$ of cases representing the main cause of neurological disorders; $53 \%$ of the cases $(186 / 354)$ were represented by viral diseases; $3.11 \%(11 / 354)$ were of parasitic etiology, $2.54 \%$ (9/354) were caused by bacteria and $1.41 \%(5 / 354)$ by fungi. Physical agents represented the second most important cause of CNS disorders with 9.89\% (35/354) and tumors third cause with 5.93\% (21/354). Other uncommon observed disorders were metabolic changes secondary to liver or kidney failure, accounting for $2.54 \%$ (9/354). Rare cases of congenital hydrocephalus were observed, $1.41 \%(5 / 354)$. The cases of neurological manifestations associated with vascular, degenerative and inflammatory noninfectious lesions, for many of which were specific cause was not established accounted for $4.24 \%$ (15/354); they were within the following disease categories: ischemic and hemorrhagic infarcts $(6 / 15)$, vasculitis fibrinoide necrosis $(5 / 15)$, intervertebral disc disease $(2 / 15)$, granulomatous meningoencephalitis $(1 / 15)$ and cholesterol granuloma $(1 / 15)$. The central nervous system disorders represent an important cause of death or reason for euthanasia in dogs in the semiarid region of Paraiba. Clinical signs vary according to the agent involved, and the location and distribution of the lesions. The knowledge of the main agents that can affect the canine CNS it is important when making a list of differential diagnosis.
\end{abstract}

INDEX TERMS: Central nervous system, dogs, diseases of dogs, encephalopathies, opportunistic infections.

RESUMO.- São descritas doenças do sistema nervoso central (SNC) em cães diagnosticadas no sertão da Paraíba. Os registros de necropsia de 1.205 cães foram revisados. Em 354 casos

\footnotetext{
${ }^{1}$ Recebido em 21 de outubro de 2016.

Aceito para publicação em 27 de abril de 2017.

${ }^{2}$ Discente do Programa de Pós-Graduação em Medicina Veterinária, Centro de Saúde e Tecnologia Rural (CSTR), Universidade Federal de Campina Grande (UFCG), Av. Universitária s/n, Bairro Santa Cecília, Patos, PB 58708-110, Brasil. *Autor para correspondência: talita frade@hotmail.com

${ }^{3}$ Graduação em Medicina Veterinária, Centro de Saúde e Tecnologia Rural (CSTR), Universidade Federal de Campina Grande (UFCG), Patos, PB, Brasil 58708-110.

${ }^{4}$ Médica Veterinária, Hospital Veterinário, Centro de Saúde e Tecnologia Rural (CSTR), Universidade Federal de Campina Grande (UFCG), Patos, PB, Brasil 58708-110.

${ }^{5}$ Docente do Programa de Pós-Graduação em Medicina Veterinária, Centro de Saúde e Tecnologia Rural (CSTR), Universidade Federal de Campina Grande (UFCG), Patos, PB, Brasil 58708-110.
}

(29,38\%) foram registrados história clínica de alterações do sistema nervoso. Duzentos e noventa e seis casos tiveram diagnóstico definitivo e 58 foram inconclusivos. As doenças infecciosas foram observadas em 59,60\% (211/354) de casos que representam a principal causa de distúrbios neurológicos; $53 \%$ dos casos (186/354) foram representadas por doenças virais; 3,11\% (11/354) foram de etiologia parasitária, 2,54\% (9/354) foram causadas por bactérias e 1,41\% (5/354) por fungos. Os agentes físicos representaram a segunda causa mais importante de transtornos do SNC com 9,89\% (35/354) e os tumores a terceira causa com 5,93\% (21/354). Outras alterações pouco frequentes foram alterações metabólicas secundárias a insuficiência hepática ou renal, representando 2,54\% (9/354). Casos raros de hidrocefalia congênita foram observados, 1,41\% (5/354). Os casos de manifestações neurológicas associadas a alterações vasculares, degenerativas e inflamatórias não infecciosas, muitas das quais uma 
causa específica não foi estabelecida representaram 4,24\% (15/354); Estavam dentro das seguintes categorias de doenças: Infartos isquêmicos e hemorrágicos (6/15), necrose vascular fibrinoide (5/15), doença do disco intervertebral (2/15), meningoencefalite granulomatosa $(1 / 15)$ e granuloma de colesterol (1/15). Os distúrbios do sistema nervoso central representam uma importante causa de morte ou eutanásia em cães na região semiárida da Paraíba. Os sinais clínicos variaram de acordo com o agente envolvido, localização e distribuição das lesões. 0 conhecimento dos principais agentes que pode afetar o SNC canino é importante ao fazer uma lista de diagnóstico diferencial.

TERMOS DE INDEXAÇÃO: Sistema nervoso central, caninos, doenças de cães, encefalopatias, infecções oportunistas.

\section{INTRODUÇÃO}

As doenças do sistema nervoso central (SNC) constituem uma importante causa de morte em cães. Em um estudo realizado nos Estados Unidos os distúrbios do SNC representaram 7,0\% das causas de morte (Craig 2001). No Brasil existem relatos pontuais, reportando uma única doença (Marcasso et al. 2005, Pavarini et al. 2007, Silva et al. 2007, Santini et al. 2010, Uchôa et al. 2012, Fernandes et al. 2013) ou categoria de doença (Santos et al. 2012). Não se conhece a frequência das doenças neurológicas de acordo com as regiões geográficas do país (Fighera et al. 2008b). Um estudo mais abrangente (Chaves et al. 2014), caracterizou as doenças neurológicas em cães atendidos em um Hospital Veterinário da região Sul do país, porém com maior ênfase na clínica.

A caracterização das doenças do SNC que causam morte ou são razão para eutanásia de cães nas diferentes regiões do Brasil servirá como um guia para auxiliar clínicos e patologistas que trabalham com doenças de pequenos animais a estabelecer diagnósticos precisos e diferenciais. Essas informações também servirão de subsídios para adoção de medidas de controle e prevenção para as patologias de cães, com o objetivo de reduzir o percentual de óbitos e contribuir para melhoria da qualidade de vida. Dessa forma, objetivou-se com este trabalho determinar as doenças do sistema nervoso central de cães diagnosticadas no sertão da Paraíba.

\section{MATERIAL E MÉTODOS}

Foram revisadas todas as fichas de necropsias realizadas em cães no Laboratório de Patologia Animal do Hospital Veterinário da Universidade Federal de Campina Grande (LPA/HV/UFCG), Campus de Patos, Paraíba, no período de janeiro de 2003 a dezembro de 2014. Foram identificadas e selecionadas as fichas que apresentavam histórico de alterações neurológicas. Dessas, avaliaram-se os dados epidemiológicos relacionados à raça, ao sexo e a idade, aos sinais clínicos e as alterações macroscópicas e microscópicas descritas. Em relação à idade, os cães foram subdivididos em três grupos de faixas etárias: filhotes (até um ano de idade), adultos (de um a nove anos de idade) e idosos (dez anos de idade ou mais), semelhante ao reportado por Fighera et al. (2008b). Os aspectos histológicos de todos os casos foram revisados. 0 material proveniente de necropsias era fixado em formol a $10 \%$, processado rotineiramente para histopatologia e corado com hematoxilina e eosina (HE). Para visualização dos agentes bacterianos as seguintes colorações especiais foram utilizadas: metenamina nitrato de prata de Grocott
(GMS), Ziehl-Neelsen modificado, Brown-Brenn modificado e Giemsa. Para visualização de agentes fúngicos utilizaram-se GMS, Ácido Periódico de Schiff (PAS) e Azul Alciano (AA). Foram selecionados blocos para realização de imuno-histoquímica (IHQ) com anticorpo monoclonal anti-cinomose canina na diluição de 1:400 e antirribonucleoproteína para o vírus da raiva na diluição de 1:1000. Nos casos de infecção por protozoários com morfologia de Toxoplasma gondii foi realizada a IHQ com anticorpo anti-T. gondii como previamente descrito por Frade et al. (2015b). Nos casos de infecções por protozoários com morfologia de ameba de vida livre foi realizada a IHQ com anticorpos anti-Naegleria sp., anti-Balamuthia sp. e anti-Acanthamoeba sp. como previamente descrito por Daft et al. (2005). Em um caso de infecção por fungo angioinvasivo com suspeita de zigomicose foi realizada IHQ com anticorpo anti-Rhizopus arrhizus na diluição de 1:50. Em outro caso sugestivo de infecção fúngica foi realizada IHQ com anticorpo anti-Candida albicans na diluição de 1:1000 e anti-Aspergillus sp na diluição de 1:300. De um caso sugestivo de feo-hifomicose foi enviado material para exame microbiológico.

As doenças foram agrupadas nas seguintes categorias: infecciosas (virais, por protozoários, bacterianas e fúngicas), distúrbios causados por agentes físicos, neoplasia, distúrbios metabólicos e distúrbios do desenvolvimento. As doenças que não puderam ser classificadas em nenhuma dessas categorias foram agrupadas como "outros distúrbios". Os neoplasmas foram classificados de acordo com as características histopatológicas.

Casos com manifestações neurológicas, nos quais as evidências não foram suficientes para estabelecer um diagnóstico definitivo, foram considerados como inconclusivos. Também foram considerados como inconclusivos todos os casos em que, embora houvesse suspeita clínica de intoxicação, faltavam exames toxicológicos e casos sugestivos de cinomose, nos quais não foram visualizados corpúsculos de inclusão viral pela HE.

Nos casos que o cão apresentava mais do que um processo patológico, um único diagnóstico definitivo foi estabelecido e considerado para cada caso.

\section{RESULTADOS}

Durante um período de 12 anos, 1.205 cães foram necropsiados. Em 354/1.205 dos casos havia histórico de alterações neurológicas, desses 296/354 tinham diagnóstico definitivo e 58/354 eram inconclusivos. As doenças do sistema nervoso central diagnosticadas no LPA/HV/UFCG encontram-se relacionadas no Quadro 1.

\section{Doenças infecciosas}

As doenças infecciosas foram as mais frequentes, 211/354, das doenças do SNC de cães. Destas, as mais comumente observadas foram as virais, sendo 179/354 casos de cinomose e 7/354 casos de hepatite infecciosa canina. Outras doenças infecciosas parasitárias, bacterianas e fúngicas, representaram 11/354, 9/354 e 5/354, respectivamente.

\section{Doenças virais}

Dos 179 casos de cinomose com sinais neurológicos, em 166 havia lesão histológica no encéfalo e/ou medula espinhal. A idade variou de 20 dias a 10 anos, 64/179 eram filhotes, 54/179 eram adultos e 8/179 idosos, e em 53 casos a idade não foi informada. Clinicamente, esses cães apresentavam sinais neurológicos, associados ou não a sinais respiratórios, digestórios e lesões cutâneas e oculares. As lesões microscópicas compatíveis com cinomose foram 
Quadro 1. Classificação das doenças do sistema nervoso central diagnosticadas em cães no Laboratório de Patologia Animal, Hospital Veterinário, Universidade Federal de Campina Grande, Patos/PB , no período de janeiro 2003 a dezembro 2014

\begin{tabular}{|c|c|c|}
\hline Categorias/Doenças/Distúrbios & № de Casos & $\%$ \\
\hline Infecciosas & 211 & 59,60 \\
\hline Virais & 186 & 52,54 \\
\hline Cinomose & 179 & 50,56 \\
\hline Hepatite infecciosa canina & 7 & 1,98 \\
\hline Parasitárias (por protozoários) & 11 & 3,11 \\
\hline Toxoplasmose* & 4 & 1,13 \\
\hline Babesiose cerebral & 4 & 1,13 \\
\hline Amebas de vida livre** & 3 & 0,85 \\
\hline Bacterianas & 9 & 2,54 \\
\hline Nocardiose* & 6 & 1,69 \\
\hline Meningoencefalite supurativa/abscessos** & 3 & 0,85 \\
\hline Fúngicas & 5 & 1,41 \\
\hline Feo-hifomicose & 2 & 0,56 \\
\hline Criptococose & 1 & 0,28 \\
\hline Mucormicose* & 1 & 0,28 \\
\hline Candidíase* & 1 & 0,28 \\
\hline Distúrbios causados por agentes físicos (traumas) & 35 & 9,89 \\
\hline Traumatismo espinomedular & 22 & 6,22 \\
\hline Traumatismo crânioencefálico & 13 & 3,67 \\
\hline Neoplasias & 21 & 5,93 \\
\hline Primárias & 4 & 1,13 \\
\hline Meningioma & 2 & 0,56 \\
\hline Oligodendroglioma & 1 & 0,28 \\
\hline Ependimoma & 1 & 0,28 \\
\hline Metastáticas & 11 & 3,11 \\
\hline Linfoma & 4 & 1,13 \\
\hline Tumor Venéreo Transmissível & 3 & 0,85 \\
\hline Hemangiossarcoma & 2 & 0,56 \\
\hline Sarcoma a & 1 & 0,28 \\
\hline Plasmocitoma & 1 & 0,28 \\
\hline $\begin{array}{l}\text { Extensão/ infiltração e compressão de medula } \\
\text { espinhal }\end{array}$ & 6 & 1,69 \\
\hline Osteossarcoma (vértebra) & 3 & 0,85 \\
\hline Rabdomiossarcoma & 2 & 0,56 \\
\hline Hemangiopericitoma & 1 & 0,28 \\
\hline Metabólicas & 9 & 2,54 \\
\hline Encefalopatia hepática & 5 & 1,41 \\
\hline Encefalopatia urêmica & 4 & 1,13 \\
\hline \multicolumn{3}{|l|}{ Distúrbios do desenvolvimento } \\
\hline Hidrocefalia & 5 & 1,41 \\
\hline Outros distúrbios & 15 & 4,24 \\
\hline Infarto cerebral & 6 & 1,69 \\
\hline Vasculite e arterite fibrinoide & 5 & 1,41 \\
\hline Doença do disco intervertebral (DDIV) & 2 & 0,56 \\
\hline Meningoencefalomielite granulomatosa (MEG) & 1 & 0,28 \\
\hline Granuloma de colesterol & 1 & 0,28 \\
\hline Inconclusivos & 58 & 16,38 \\
\hline TOTAL & 354 & 100 \\
\hline
\end{tabular}

* Co-infecção pelo vírus da cinomose canina (VCC), ** 2 casos associados

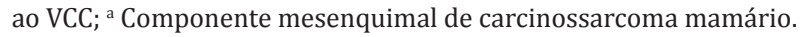

caracterizadas principalmente por desmielinização da substância branca do cerebelo associada a corpúsculos de inclusão eosinofílicos intranucleares em astrócitos (Fig.1A). Além de meningite/encefalite e/ou mielite não supurativa. Em alguns casos também foram observadas áreas de malacia com numerosas células Gitter, principalmente associadas às áreas de desmielinização. Também foi observado necrose neuronal laminar cortical, esferoides axonais, câmaras de digestão, astrócitos hipertróficos e gemistócitos, por vezes com formação de sincícios. Corpúsculos de inclusão eosinofílicos intracitoplasmáticos e/ou intranucleares também foram observados em células ependimárias, gemistócitos, neurônios e oligodendrócitos.

Em um dos casos onde havia apenas corpúsculos de inclusão eosinofílicos intracitoplasmáticos em células de Purkinje do cerebelo, o diagnóstico de cinomose foi confirmado através da imunomarcação positiva com anticorpo anti-cinomose canina $\mathrm{e}$ ausência de marcação para raiva com antirribonucleoproteína.

Foram diagnosticados sete casos de hepatite infecciosa canina (HIC) com envolvimento do SNC. A maioria dos cães acometidos eram adultos (4/7), com idade variando entre dois e sete anos, e três jovens com idade variando entre dois meses e um ano. 0 curso clínico variou de hiperagudo a agudo, com duração de até quatro dias. Foram acometidos quatro machos e três fêmeas, dois da raça Poodle e cinco sem raça definida (SRD). Os sinais clínicos observados em ordem decrescente foram convulsões, apatia, inapetência/anorexia, diarreia, hematúria, epistaxe, petéquias, vômitos, edema submandibular e vocalização. Alterações macroscópicas no encéfalo foram evidenciadas em apenas um caso, caracterizadas por áreas multifocais de hemorragias. Microscopicamente no encéfalo verificou-se vasculite, necrose fibrinoide, congestão e hemorragia perivascular associado a corpúsculos de inclusão intranucleares basofílicos no endotélio vascular no encéfalo (Fig.1B). Em todos os casos de HIC, foram observadas lesões no fígado caracterizadas por necrose e hemorragia centrolobular associada às inclusões intranucleares em hepatócitos.

\section{Doenças parasitárias}

Dos quatro casos de toxoplasmose, todos os casos eram adultos, com idade variando de 3,7 a 8 anos, sendo três fêmeas e um macho, três SRD e um Pinscher. Os sinais clínicos eram caracterizados principalmente por alterações neurológicas, respiratórias e lesões oculares, sugestivos de infecção pelo vírus da cinomose canina (VCC), caracterizados por mioclonias, ataxia, convulsões, andar em círculos, paresia, síndrome vestibular, estrabismo, prostração, além de diarreia, secreção ocular e nasal, e tosse. Três desses casos foram descritos por Frade et al. (2015a).

Microscopicamente, a toxoplasmose era caracterizada por áreas multifocais de malacia, associadas a estruturas arredondadas fortemente basofílicas, delimitadas por uma fina parede medindo aproximadamente de 5 a $70 \mu \mathrm{m}$, preenchidas por numerosas estruturas basofílicas alongadas, correspondentes aos bradizoítos, características de Toxoplasma gondii. Circundando essas áreas havia infiltrado inflamatório linfohistioplasmocitário com raros neutrófilos. Em algumas áreas havia predomínio de malacia com numerosas células Gitter. Essas lesões eram distribuídas predominantemente em ordem decrescente em pedúnculos cerebelares, além 

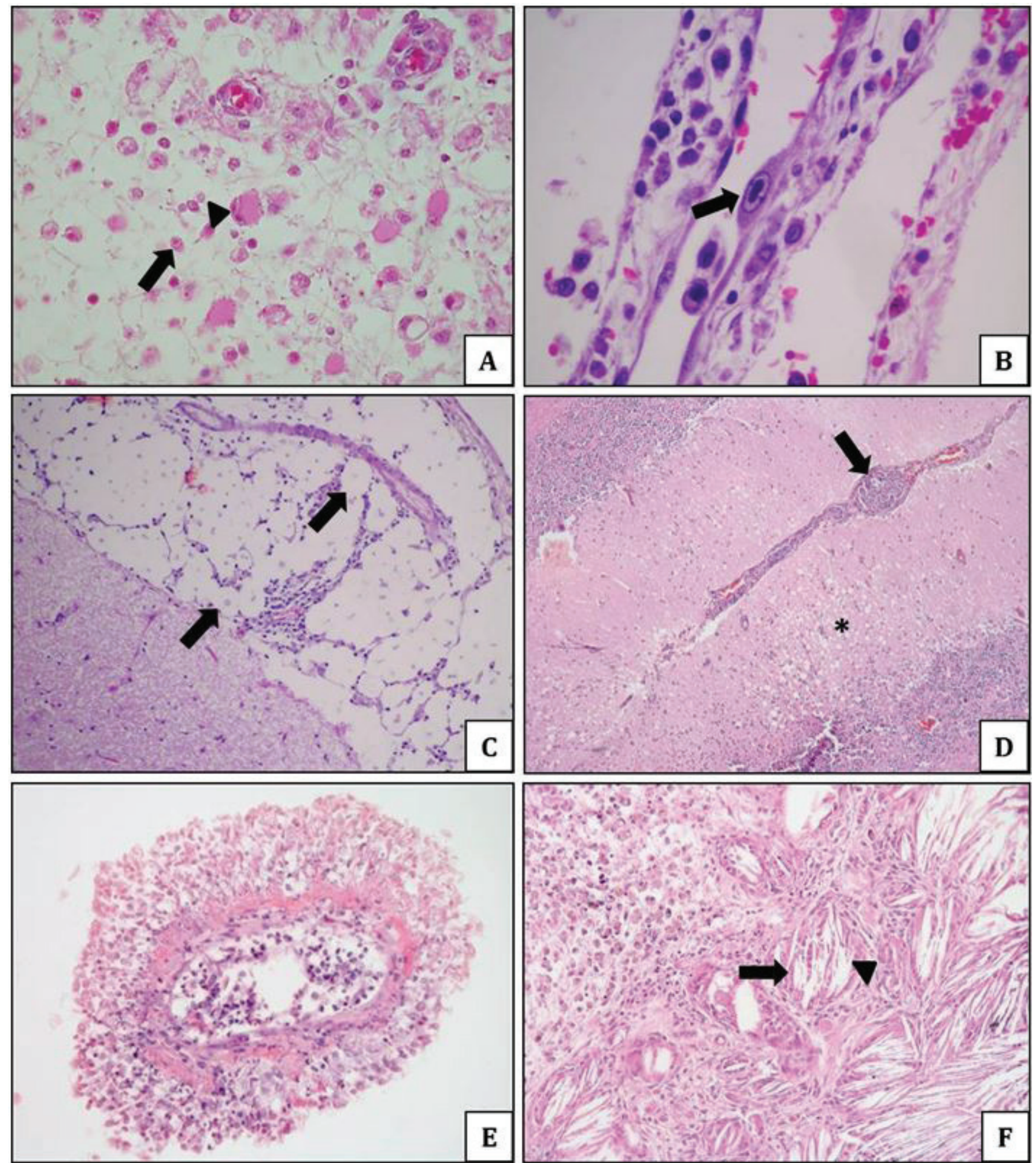

Fig.1. Doenças do sistema nervoso central de cães. (A) Cinomose, substância branca do cerebelo, observa-se corpúsculos de inclusões eosinofílicos intranucleares em astrócitos (seta) e gemistócitos (cabeça de seta), além de malacia e células Gitter. HE, obj.40x. (B) Hepatite infecciosa canina, cérebro, observa-se corpúsculo de inclusão basofílico intranuclear em endotélio vascular (seta). HE, obj.40x. (C) Criptococose, cérebro, observa-se espessamento das leptomeninges por miríades de estruturas leveduriformes (setas) compatíveis com Cryptococcus sp. HE, obj.20x. (D) Infarto isquêmico, substância cinzenta do cerebelo, observa-se êmbolo neoplásico (seta) associado à área focal discreta de espongiose (asterisco). HE, obj.20x. (E) Vasculite e necrose fibrinoide, vaso da leptomeninge do bulbo, observa-se intensa hialinização da camada média e infiltrado predominantemente neutrofílico na parede. HE, obj.20x. (F) Granuloma de colesterol, cérebro, observam-se fendas de cristais de colesterol (seta) circundadas por tecido conjuntivo e macrófagos espumosos (cabeça de seta). HE, obj.20x. 
de córtices, cerebelo, núcleos da base, tálamo e hipocampo. Na IHQ ocorreu imunomarcação positiva em todos os casos.

Os casos de babesiose com envolvimento do SNC foram caracterizados por acometer cães jovens, (dois cães com cinco meses e um com três meses) e um adulto (com 2 anos), destes três eram SRD e um Poodle, sendo dois machos e duas fêmeas. 0 curso clínico variou de 24 horas a cinco dias. Os sinais clínicos descritos eram caracterizados por vocalização, midríase, convulsões e coma, além de anorexia, apatia, dispneia, vômito, diarreia e icterícia e urina escura.

Macroscopicamente os cães apresentavam-se magros, com mucosas pálidas a discretamente ictéricas, fígado alaranjado, esplenomegalia, urina e rins escuros. 0 encéfalo estava pálido com discreta evidenciação de vasos das leptomeninges.

Microscopicamente verificou-se discreta meningoencefalite não supurativa com vasculite, edema perivascular e leucocitostase em córtices frontal, parietal, temporal e occipital, tálamo, hipocampo, plexo coroide, cerebelo, ponte e bulbo. Observou-se nas hemácias estruturas basofílicas redondas, ovais ou alongadas, de aspecto piriforme, únicas, em pares ou em grupos de quatro, morfologicamente compatíveis com Babesia sp.

Dos três casos de infecções por amebas de vida livre, em dois foi realizada a IHQ e estão descritos por Frade et al. (2015b). $\mathrm{Na}$ IHQ os dois casos foram positivos para Acanthamoeba sp. e negativos para Naegleria sp. e Balamuthia sp. Nesses casos havia ainda associação com o vírus da cinomose canina, confirmados pela histopatologia.

No terceiro caso de infecção por amebas de vida livre, foi acometido um Cocker Spaniel, macho, cinco anos de idade que apresentou convulsões, vocalização, paresia e morte com 24 horas. Macroscopicamente as lesões eram restritas ao encéfalo caracterizadas por áreas avermelhadas irregulares principalmente nas cavidades ventriculares (Fig.2A).

Microscopicamente em córtex parietal e temporal, tálamo, hipocampo e cerebelo havia meningoencefalite piogranulomatosa com vasculite e necrose fibrinoide associado a amebas intralesionais, necrose neuronal laminar nas camadas mais internas do córtex temporal. Em meio à lesão, observaram-se discretas estruturas arredondadas basofílicas, variando aproximadamente de 20 a $30 \mu \mathrm{m}$ de diâmetro, que tinham núcleo redondo com um cariossomo conspícuo excêntrico rodeado por um halo claro e citoplasma granular ou vacuolar, morfologicamente sugerindo trofozoítos de ameba.

\section{Doenças bacterianas}

Dentre as doenças bacterianas, seis casos eram de nocardiose. A identificação de Nocardia sp. foi realizada pelas características morfológicas e histoquímicas do agente através da visualização de estruturas filamentosas, ramificadas, não septadas impregnadas pela prata, coradas em vermelho pelo Ziehl-Neelsen modificado, em azul pelo Brown-Brenn modificado e róseo pálido pelo Giemsa.

Foram acometidos filhotes e adultos, com idade variando de 3 meses a três anos e sete meses, sendo quatro machos e duas fêmeas, todos SRD. Dos seis casos, apenas um não apresentava co-infecção pelo VCC. Os sinais clínicos caracterizavam-se por secreção ocular e nasal purulenta, tosse, estertores pulmonares, dispneia, convulsões, vocalização, hiperreflexia, nistagmo, agressividade e espasticidade, além de nódulos cutâneos ulcerados na região cervical e inguinal, fistulas drenando pus na região axilar e pústulas inguinais. Macroscopicamente, a lesão no SNC variava de focal a multifocal, apresentando-se avermelhada a acinzentada, de aspecto nodular, por vezes com cavitações, causando assimetria dos hemisférios cerebrais, afetavam principalmente córtices, tálamo, cerebelo, ponte, núcleos da base, hipocampo, lobo piriforme, bulbo e medula torácica. Lesões semelhantes foram observadas em órgãos das cavidades torácica e abdominal, pele e subcutâneo. Estavam afetados pulmões, pleura parietal, linfonodos traqueobrônquicos, cervical superficial, inguinal e axilar, rins, fígado, coração, diafragma, omento e serosa de estômago e intestino.

Microscopicamente em todos os órgãos afetados verificou-se infiltrado constituído predominantemente por macrófagos epitelioides, além de neutrófilos, íntegros e degenerados, formando pio/granulomas. Esses macrófagos distribuíam-se muitas vezes em formas de múltiplas estruturas semelhantes à pseudorrosetas.

Três casos foram sugestivos de infecção bacteriana, pelas características morfológicas das lesões, com predomínio de neutrófilos íntegros e degenerados. No entanto, nas colorações histoquímicas não foi visualizado agente. Foram acometidos cães SRD, sendo um macho e uma fêmea, ambos de três meses de idade e um macho de oito anos. Macroscopicamente nesses casos havia espessamento das leptomeninges por exsudato purulento, além de conteúdo purulento em ventrículos laterais e na substância branca em córtex frontal. 0 diagnóstico histopatológico foi de meningoencefalite supurativa, multifocal a coalescente, acentuada.

\section{Doenças fúngicas}

As infecções fúngicas foram observadas em filhotes, adultos e idosos, com idade variando entre cinco meses e 10 anos, sendo quatro machos e uma fêmea, das raças Cocker Spaniel, Pitt bull, Pastor Alemão, Poodle e SRD.

O primeiro caso de feo-hifomicose foi descrito por Uchôa et al. (2012). O segundo caso ocorreu em uma fêmea Pitt bull de um ano de idade, que apresentou convulsões e morte em 24 horas. Foi informado também que demonstrava anorexia e perda de peso. Macroscopicamente havia lesões nodulares, amareladas, multifocais a coalescentes, no fígado, rim e encéfalo. No encéfalo observou-se área focal avermelhada na superfície das leptomeninges do córtex occipital direito e também assimetria do hemisfério cerebral esquerdo, que ao corte após a fixação havia áreas irregulares multifocais acinzentadas e friáveis na substância cinzenta dos córtices parietal esquerdo e occipital direito. As lesões microscópicas eram semelhantes nos órgãos afetados. Histologicamente verificou-se hepatite, nefrite e meningoencefalite granulomatosa e necrosante, multifocal a coalescentes, associadas a fungos dematiáceos intralesionais, caracterizados por estruturas tubuliformes ou balonosas, septadas, marrom-amareladas pela HE, PAS e GMS. Em corte histológico desparafinizado e não corado havia hifas septadas pigmentadas, morfologicamente compatíveis com feo-hifomicetos. Na cultura microbiológica foi realizado isolamento de colônias fúngicas características de Cladophialophora bantiana.

O caso de criptococose acometeu um cão da raça Pastor Alemão, de um ano de idade, que apresentou sangramento nasal, prostração e choque com evolução de oito dias. Foi relatado ainda que havia coabitação com pombos. As lesões macroscópicas estavam restritas aos pulmões 

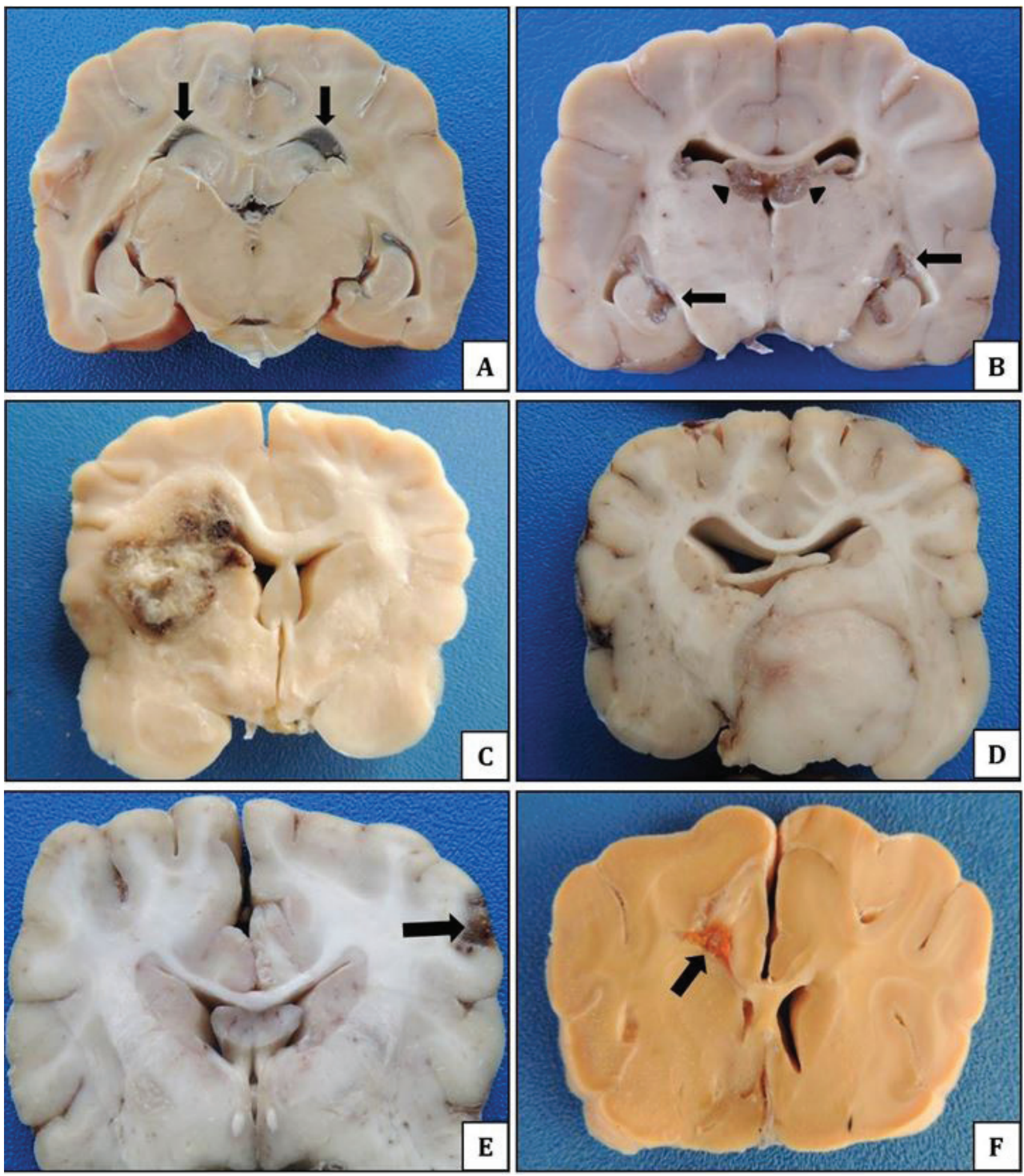

Fig.2. Doenças do sistema nervoso central de cães. Cortes transversais de encéfalos após fixação. (A) Amebíase cerebral primária, observam-se ventrículos laterais preenchidos por conteúdo vermelho-enegrecido (setas). (B) Criptococose, espessamento das leptomeninges (setas) e pequenas cavitações irregulares estendendo-se ao tálamo preenchidas por material translúcido e gelatinoso (cabeças de setas). (C) Ependimoma, observa-se massa tumoral esbranquiçada entremeada por áreas avermelhadas estendendo-se do ventrículo lateral esquerdo ao núcleo caudado. (D) Metástase de tumor venéreo transmissível metastático, observa-se assimetria dos hemisférios cerebrais, com presença de massa tumoral esbranquiçada na região de tálamo. (E) Infarto hemorrágico, área focal vermelho-enegrecida na substância cinzenta cortical em córtex temporal (seta). (F) Granuloma de colesterol, observa-se no hemisfério esquerdo área focal alaranjada no sulco do cíngulo de córtex parietal (seta). 
e encéfalo. Nos pulmões observaram-se múltiplas áreas avermelhadas discretas e elevadas da superfície pleural que se aprofundavam ao corte. Em cortes transversais do encéfalo após a fixação, havia espessamento das leptomeninges por material translúcido, gelatinoso e levemente granular, mais acentuado no terceiro ventrículo, cerebelo e córtex cerebral, causando pequenas cavitações irregulares e compressão no tecido nervoso adjacente como tálamo (Fig.2B) e substância cinzenta cortical. Histologicamente havia pneumonia piogranulomatosa, multifocal, discreta e meningoencefalite granulomatosa, multifocal, moderada, associada a estruturas fúngicas leveduriformes intralesionais (Fig.1C). Na HE as leveduras, eram arredondadas, com célula central basofílica contendo um núcleo, circundada por um halo claro. No AA a cápsula era corada fortemente em azul com aspecto radiado. No GMS a parede e o núcleo estavam impregnados e no PAS a célula foi corada em rósea, compatíveis com Cryptococcus sp. Além dessas alterações, havia também vasculite e necrose fibrinoide disseminada.

O caso de mucormicose afetou um Poodle, macho, de dez anos de idade que apresentou anorexia, apatia e ataxia com evolução de três dias. As lesões macro e microscópicas foram observadas nos pulmões, coração e encéfalo. Nos pulmões havia áreas multifocais irregulares vermelho-enegrecidas, firmes, e com superfície irregular amarelada. No coração havia área amarelada focal no ápice que se estendia do epicárdio até o endocárdio. No córtex frontal direito observaram-se vasos das leptomeninges congestos, circundados por área avermelhada irregular, que se aprofundava ao corte. Histologicamente havia broncopneumonia, miocardite e meningoencefalite piogranulomatosa acentuada e necrosante associada a hemorragia com hifas fúngicas intralesionais. Verificou-se também no encéfalo infartos, discreta malacia, presença de necrose fibrinoide dos vasos da substância branca e cinzenta e leucocitostase moderada. No encéfalo a lesão era vista espessando meninges e neurópilo adjacente em córtices frontal, parietal e temporal, núcleos da base, tálamo e hipocampo. As hifas fúngicas eram caracterizadas por estruturas irregulares, tubulares, não septadas, espessas, formando projeções dicotômicas ou em $90^{\circ}$ graus, com ocasional dilatação balonosa terminal, parede eosinofílica e em seu interior imagem negativa, compatível com zigomiceto pela HE. Na IHQ realizada ocorreu imunomarcação positiva com anticorpo anti-Rhizopus arrhizus. Observaram-se ainda inclusões intranucleares virais eosinofílicas em células ependimárias compatíveis com infecção pelo VCC.

O caso de infecção por Candida sp. acometeu um cão, macho, SRD, cinco meses de idade que apresentou apatia e incoordenação. Macroscopicamente após fixação do encéfalo e realização de cortes transversais observou-se assimetria dos hemisférios, com aumento de volume principalmente em córtex parietal esquerdo que se estendia ao neurópilo adjacente e córtex frontal, com áreas multifocais irregulares avermelhadas e acinzentadas. Histologicamente havia meningoencefalite piogranulomatosa multifocal a coalescente, acentuada, associada a estruturas tubuliformes de paredes finas e paralelas, septadas, coradas levemente basofílicas pela HE, coradas em vermelho pelo PAS e impregnadas pelo GMS. Morfologicamente compatíveis com Candida sp. Na IHQ realizada a imunomarcação foi positiva para o anticorpo anti-Candida sp., e negativa para o anticorpo anti-Aspergillus sp.

\section{Distúrbios causados por agentes físicos}

Os distúrbios causados por agentes físicos representaram 35/296 das causas de morte ou razão para eutanásia. Dos casos em que foi possível estabelecer as causas dos traumas, 14 estavam relacionados a atropelamentos por veículos automotivos e três por brigas entre cães. A maioria dos cães era errante e não tinha informações da causa do trauma. A faixa etária variou entre jovens e adultos, ocorrendo predominantemente em filhotes.

Vinte e dois casos foram identificados como traumatismo espinhal-medular e treze casos como traumatismo cranioencefálico.

Dos 22 casos de traumatismo espinomedular, 50\% apresentavam lesões na região torácica (11/22), em 27,27\% na região lombar (6/22) e 9,09\% na região cervical $(2 / 22)$. Em $13,63 \%$ dos casos $(2 / 22)$ não foi citado o segmento afetado. Em todos esses casos havia lesão na medula espinhal, que incluía compressão medular pelo fragmento ósseo deslocado, laceração e hemorragia. Na maioria dos casos de traumatismo crânioencefálico, foram evidenciadas fraturas em ossos do crânio, embora em alguns tenham sido evidenciadas apenas lesão no encéfalo. As lesões encefálicas observadas incluíam hemorragias localizadas principalmente no espaço subaracnóideo, intracerebral e subdural, além de ruptura da dura-máter, muitas vezes com laceração decorrente de penetração de esquírolas ósseas na substância encefálica.

\section{Neoplasias}

As alterações neurológicas decorrentes de neoplasmas estiveram presentes em $21 / 354$ casos, sendo $19 \%$ primários do tecido nervoso (4/21) e 81\% (17/21) secundários. Dos dezessete casos de acometimento secundário, onze foram por metástases (sendo nove para o encéfalo e dois para medula espinhal) e seis por extensão/infiltração de estruturas vizinhas para o canal medular com compressão da medula espinhal.

Dentre os primários, foram diagnosticados dois casos de meningiomas, um oligodendroglioma e um ependimoma (Fig.2C). Dos neoplasmas metastáticos verificaram-se quatro linfomas, três tumores venéreos transmissíveis (Fig.2D), dois hemangiossarcomas, um sarcoma (componente mesenquimal de carcinossarcoma mamário) e um plasmocitoma. Por extensão ocorreram três osteossarcomas e por infiltração de estruturas adjacentes dois rabdomiossarcomas e um hemangiopericitoma.

Em 61,90\% dos casos (13/21) ocorreram disfunções neurológicas encefálicas, sendo que um destes também havia envolvimento medular. Em 38,10\% (8/21) havia somente disfunção neurológica medular. Dos cães acometidos, sete eram SRD, cinco da raça Rottweiler, três da raça Pinscher, dois da raça Boxer, um Pastor Branco e um Poodle. Em dois casos não havia informação sobre a raça. Quanto ao sexo, onze eram machos e dez eram fêmeas. Quanto a idade, $81 \%$ $(17 / 21)$ tinham idade igual ou superior a cinco anos, variando entre cinco anos e 16 anos, dois cães eram jovens, um com sete meses foi diagnosticado com linfoma e um com 1 ano e 4 meses diagnosticado com oligodendroglioma. Em dois casos a idade não foi informada.

Os sinais clínicos variaram de acordo a localização e distribuição das neoplasias. Os principais sinais clínicos que caracterizaram o envolvimento focal de telencéfalo foram convulsões, cegueira, vocalização, sonolência, obnubilação, mudança de comportamento e não reconhecimento do dono. 
Os sinais clínicos que caracterizavam o envolvimento focal medular foram paresia e paraplegia de membros pélvicos. Já as regiões de tronco e cerebelo, a distribuição ocorreu multifocal, por vezes com associação de lesões em telencéfalo e medula, caracterizados por incoordenação, cegueira, opistótono, andar em círculos, estrabismo ventromedial, compressão da cabeça contra obstáculo, obnubilação, ausência de reflexo de ameaça e síndrome de Schiff-Sherrington.

\section{Distúrbios metabólicos}

As doenças metabólicas que desencadearam alterações neurológicas representaram 9/354 das causas de morte, sendo 5 casos de encefalopatias hepáticas e 4 casos de encefalopatias urêmicas.

Os casos de encefalopatia hepática foram observados em cães adultos (4/5), com idade variando entre seis e nove anos, e em um caso cão era idoso, com 13 anos de idade. Foram acometidos três machos e duas fêmeas, sendo dois cães sem raça definida, Pit bull, Pastor alemão e Cocker spaniel. As manifestações clínicas neurológicas foram caracterizadas por convulsões, decúbito e hiperextensão de membros, apatia, incoordenação e sonolência. Além destes, havia outros sinais clínicos associados à insuficiência hepática, incluindo vômitos, fezes pastosas, ascite, edema subcutâneo, anorexia, inapetência, desidratação, e arritmia cardíaca (1/5). 0 comprometimento hepático em dois casos estava associado à cirrose e em três casos a neoplasmas, sendo dois leiomiossarcoma e um carcinoma hepatocelular. Em todos os casos foram observados desvios portossistêmicos adquiridos.

As lesões microscópicas observadas no encéfalo desses casos eram distribuídas em córtices frontal, parietal e temporal, caracterizadas por aumento do espaço perivascular e perineuronal, além de tumefação endotelial. Havia também discreta tumefação de astrócitos e presença de astrócitos de Alzheimer tipo II. Em um caso verificou-se também hialinização da camada média de arteríolas na substância cinzenta.

As encefalopatias urêmicas que desencadearam manifestações neurológicas estavam associadas à insuficiência renal crônica, sendo um caso de fibrose renal, um de displasia renal e um de glomerulonefrite membranoproliferativa, e um caso de insuficiência renal aguda devido à nefrose tubular aguda tóxica. Foram acometidos cães das raças Poodle, Pinscher, Labrador e um SRD, com idade entre três e quatro anos. As manifestações neurológicas foram caracterizadas por apatia, desorientação e convulsões. Outras manifestações observadas foram anorexia, dispneia, edema, diarreia, dor abdominal, hálito urêmico e vômitos. Não foram observadas alterações morfológicas significativas no SNC.

\section{Distúrbios do desenvolvimento}

Os casos de hidrocefalia representaram 5/354 e todos estavam relacionados à forma congênita. A doença foi observada em cães jovens, entre dois (3/5) e três meses (2/5) de idade, sendo três cães SRD e dois Pinschers. As manifestações clínicas foram variáveis e caracterizadas por apatia, inconsciência, hipersensibilidade, paralisia espástica, estrabismo, andar em círculos, pressão da cabeça contra objetos, sonolência, opistótono, decúbito e convulsão, de forma isolada ou associada. Três cães apresentaram aumento de volume craniano. Na necropsia, além do aumento de volume craniano, observou-se edema do cérebro com diminuição dos giros e sulcos e acumulo de líquor. Ao corte seriado dos encéfalos, após a fixação em formol, pôde-se observar a distensão dos ventrículos laterais em todos os casos, sendo que em dois deles também havia dilatação do terceiro ventrículo e em um do aqueduto mesencefálico. Em um dos casos, além da distensão dos ventrículos laterais, havia parcial desaparecimento do septo pelúcido que separa os ventrículos laterais e diminuição da espessura da substância branca e cinzenta.

\section{Outros distúrbios}

Nessa categoria estão relacionados os casos de manifestações neurológicas associadas a lesões vasculares, degenerativas e inflamatórias não infecciosas, dos quais muitos não foram possíveis estabelecer uma causa específica, que representaram $15 / 354$.

Dos seis casos de infarto cerebral, quatro foram classificados como infartos isquêmicos e dois hemorrágicos. Nos casos de infarto isquêmico, dois estavam associados à septicemia, um a êmbolos neoplásicos (carcinoma mamário) e um não identificado. Os casos hemorrágicos foram atribuídos a tromboembolismo séptico secundário a endocardite valvar bacteriana, sendo um na valva atrioventricular esquerda e semilunar aórtica e outro restrito a semilunar aórtica. Foram afetados quatro machos e duas fêmeas, sendo três SRD, e demais das raças Dobermann, Poodle e Pastor alemão. Quanto à idade, os cães eram predominantemente idosos, variando entre 10 e 16 anos. Apenas um cão era jovem, com dois anos de idade. Os sinais clínicos neurológicos eram caracterizados por apatia, nistagmo, vocalização, convulsões, hiperextensão de membros e estupor. As lesões macroscópicas no SNC foram evidenciadas nos dois casos de infarto hemorrágico, caracterizadas por áreas avermelhadas, irregulares, multifocais, na superfície cortical que se aprofundavam ao corte, limitadas a substância cinzenta (Fig.2E). Microscopicamente havia área focalmente extensa de necrose e hemorragia em córtex temporal direito em um caso e no outro a lesões semelhantes distribuídas na substância cinzenta em córtices temporal e occipital, hipocampo, tálamo e medula cervical. Em algumas áreas verificaram-se também raros neutrófilos íntegros e degenerados. As lesões microscópicas observadas nos infartos isquêmicos afetavam ponte, córtex cerebelar e córtex cerebral. Havia moderada espongiose, e necrose das células da glia e de neurônios (Fig.1D). Além das alterações isquêmicas, em um caso observaram-se trombos de fibrina na luz de capilares, além de discreto edema e hemorragia perivascular.

Os casos de lesões vasculares caracterizadas por vasculite e necrose fibrinoide representaram 5/354, e ocorreram predominantemente de forma disseminada (4/5). Em apenas um caso a vasculite ficou restrita ao encéfalo. Foram afetadas três fêmeas e dois machos, sendo dois Pinschers, dois Poodles e um SRD. Quanto à idade, foi observado principalmente em cães adultos, com idade variando de 7 a 13 anos, e em um filhote de 2 meses. Os sinais clínicos neurológicos foram pouco evidentes, caracterizados por apatia, sinais cerebelares, vocalização e coma. Em apenas um caso foi observado lesões macroscópicas, caracterizadas por achatamento das circunvoluções dos telencéfalo e discreta dilatação dos ventrículos laterais.

Estavam afetados os vasos das leptomeninges e/ou do neurópilo em córtices, núcleos da base, plexo coroide, cerebelo e bulbo (Fig.1E), além de vasos na submucosa da bexiga, interstício renal e miocárdio. 
Em $0,56 \%$ dos casos $(2 / 354)$ as alterações neurológicas foram atribuídas à doença do disco intervertebral (DDIV). Os dois casos ocorreram em cães Rottweiler, ambos machos, um com 12 anos e o outro com sete anos e oito meses, com histórico de dificuldade para andar, evoluindo para paresia e decúbito. Na necropsia observou-se herniação e protrusão do disco intervertebral causando compressão da medula espinhal, sendo um entre L2 - L3 e outro entre as vertebras cervicais C3-C5.

A meningoencefalite granulomatosa observada em um caso, ocorreu em uma cadela Poodle, de quatro anos de idade, que apresentava apatia e paresia de membros torácicos e pélvicos. Macroscopicamente não foram observadas lesões significativas. Microscopicamente no cerebelo havia acentuado infiltrado inflamatório predominantemente histiocítico, além de linfócitos, plasmócitos e raros neutrófilos, formando manguitos perivasculares, principalmente na substância branca e nas leptomeninges. Também havia acentuada malacia na substância branca, com numerosas células Gitter. Lesão semelhante foi observada nos pedúnculos cerebelares, córtices, tálamo e medula cervical. A imuno-histoquímica realizada com anticorpo anti-cinomose canina foi negativa.

Em um caso foi observado granuloma de colesterol em cão macho, SRD, de um ano e onze meses, que manifestou sinais de insuficiência renal crônica em decorrência de displasia renal. Macroscopicamente observou-se espessamento da dura-máter na região de córtex frontal, adjacente apresentava área focal de coloração amarronzada à esbranquiçada no sulco da circunvolução. Após fixação do encéfalo e realização de cortes transversais, observou-se no hemisfério esquerdo área focal alaranjada no sulco do cíngulo de córtex parietal, face medial, ligeiramente se estendendo ao corpo caloso (Fig.2F). Na microscopia em córtex parietal, desde as leptomeninges ao neurópilo adjacente, observou-se área focalmente extensa contendo numerosas fendas de cristais de colesterol, caracterizadas por espaços vazios paralelos, circundadas por traves de tecido conjuntivo com numerosos macrófagos espumosos e células gigantes multinucleadas (Fig.1F), além de discretas áreas multifocais de mineralização. Havia também numerosos grânulos de hemossiderina no citoplasma de macrófagos em meio ao granuloma e no neurópilo adjacente e moderada gliose.

\section{Inconclusivos}

Dos 58 casos inconclusivos, em 25 não foram observadas alterações que justificassem os sinais neurológicos. Dezessete eram sugestivos de cinomose, porém não foram visualizados corpúsculos de inclusão para confirmar a suspeita clínica ou não foi possível encontrar material para revisão. Em doze casos havia suspeita clínica de intoxicação, entretanto não foram evidenciadas lesões histológicas significativas e nem foi possível realizar exame toxicológico para confirmação. Em três casos o material analisado encontrava-se impróprio para o exame histológico. Em apenas um caso verificou-se área focal de malacia e hemorragia, porém não foi possível estabelecer a causa.

\section{DISCUSSÃO}

As doenças do sistema nervoso central representaram uma importante causa de morte ou razão para eutanásia em cães na região semiárida da Paraíba. Dessas, as mais importantes foram as de causa infecciosa. Em estudos que reportaram a causa de morte em cães, esse achado foi semelhante (Bentubo et al. 2007, Fighera et al. 2008b, Trapp et al. 2010), porém difere de estudos realizados em clínicas veterinárias (Fluehmann et al. 2006, Chaves et al. 2014).

Dentre as doenças infecciosas aqui relatadas as mais importantes foram as virais, com maior relevância para cinomose, que representou $14,85 \%$ do total de causas de morte e $60,68 \%$ das causas de acometimento do SNC. Outros estudos demonstram resultados semelhantes, com a cinomose estando entre as principais causas de morte (Headley \& Graça 2000, Silva et al. 2007, Fighera et al. 2008b, Sonne et al. 2009, Chaves et al. 2014, Frade 2014), As doenças infecciosas tratam-se de um fator de risco bem caracterizado, que reduz a expectativa de vida dos cães no Brasil (Bentubo et al. 2007), sendo a cinomose ainda a principal causa de morte em cães neste país.

Essa alta frequência de doenças infecciosas pode ser explicada pela baixa adesão aos programas de vacinação, administração incorreta da vacina em imunossuprimidos ou protegidos de forma passiva, vacinação quando os cães já estão infectados e ainda a utilização de vacinas mal armazenadas (Fighera et al. 2008b, Tizard 2014).

As infecções concomitantes foram frequentes neste estudo, tais como a nocardiose, toxoplasmose, acanthamoebíase, mucormicose e candidíase que tiveram a cinomose como fator predisponente. Além da redução da expectativa de vida em cães, a cinomose também é uma importante causa de imunossupressão (Zachary 2013). Algumas dessas doenças sistêmicas com o comprometimento do SNC já foram relatadas em associação com o vírus da cinomose canina, como infeções bacterianas por Nocardia sp. (Fawi et al. 1971) e por protozoários, como Toxoplasma gondii (Silva et al. 2007, Frade et al. 2015b) e Acanthamoeba sp. (Reed et al. 2010, Frade et al. 2015a), porém constituem relatos pontuais. É importante ressaltar que na maioria dos casos os sinais neurológicos apresentados pela cinomose quando isolada ou em associação com outros agentes e demais doenças infecciosas foram indistinguíveis, com a primeira suspeita desses casos sendo a cinomose.

Nos casos de infecção pelo Adenovirus canino -1 (CAV 1), as principais suspeitas iniciais eram erliquiose, intoxicação e parvovirose. 0 diagnóstico clínico de HIC é difícil devido ao curso superagudo ou agudo da enfermidade e a pouca especificidade dos sinais clínicos (Inkelmann et al. 2007), devendo-se sempre incluir HIC no diferencial quando um cão apresentar curso clínico com duração de algumas horas a quatro dias com distúrbios neurológicos, gastrointestinais e hemorragias na pele e mucosas. As manifestações neurológicas em infecções pelo CAV-1 são raras (Caudell et al. 2005), porém estiveram presentes nesse estudo e já foi relatada em 15/45 casos de HIC relatados por Inkelmann et al. (2007). Caudell et al. (2005) descreve a possibilidade de variação de estirpes virais em relação ao tropismo endotelial no SNC. A presença de hemorragias, incluindo o SNC, é uma característica da doença, e provavelmente se deve há mais de um fator, além da lesão direta devido ao tropismo do vírus por células endoteliais, hepatócitos e mesotélios (Greene 2012), ocorre a incapacidade do fígado em sintetizar fatores da coagulação e a coagulação intravascular disseminada (Wigton et al. 1976).

Dentre os casos de infecções bacterianas, foram predominantes as infecções por Nocardia sp. Apesar de pouco frequente o 
acometimento do SNC (Ribeiro \& Condas 2016), neste estudo ocorreu em mais da metade dos casos. A observação nestes casos em associação com o VCC muitas vezes mascara e dificulta um diagnóstico clínico de nocardiose.

Em dois, dos três casos de infecções por amebas de vida livre, as lesões foram atribuídas aos protozoários do gênero Acanthamoeba sp., confirmados através da imuno-histoquímica. Na região semiárida da Paraíba já foram descritas as infecções pelos gêneros Acanthamoeba sp. em cães (Frade et al. 2015a) e Naegleria sp. em bovino (Pimentel et al. 2012). Na espécie canina já foram relatadas infecções por Acanthamoeba sp. e Balamuthia mandrillaris que apresentaram o comprometimento sistêmico associado a imunossupressão (Bauer et al. 1993, Foreman et al. 2004, Dubey et al. 2005, Reed et al. 2010, Kent et al. 2011). No último caso de infecção por ameba de vida livre, alguns dados como a ausência de imunossupressão e de lesões sistêmicas, sugerem se tratar possivelmente de outro gênero, Naegleria fowleri, semelhante ao reportado por Pimentel et al. (2012), que é caracterizada por uma meningoencefalite amebiana primária (MAP) em humanos e animais imunocompetentes (Martinez \& Visvesvara 1997).

Apesar da babesiose ser uma doença comum na rotina clínica, sua forma neurológica é incomum. Através da disseminação hematógena em eritrócitos, os protozoários chegam aos capilares sanguíneos, em especial do cérebro, causando infecção grave (Greene 2012). Deve-se suspeitar quando da ocorrência de sinais neurológicos em cães jovens, com evolução aguda a hiperaguda, manifestando principalmente anemia, icterícia e hemoglobinúria, associados a presença de carrapatos.

Dentre os dois casos diagnosticados de feo-hifomicose, em um foi realizado isolamento de Cladophialophora bantiana, que apresenta tropismo pelo tecido nervoso e consequentemente é o mais isolado e observado nas formas sistêmica e cerebral da feo-hifomicose (Poutahidis et al. 2009). Desta forma, apesar da não realização do cultivo e isolamento no primeiro caso relatado por Uchôa et al. (2012), é possível que esta espécie também estivesse relacionada com o desencadeamento da doença. Embora a forma cutânea e subcutânea da feo-hifomicose sejam mais frequentemente relatadas em cães e gatos (Sisk \& Chandler 1982, McKenzie et al. 1984, Herráez et al. 2001, Abramo et al. 2002), a forma sistêmica e cerebral vem cada vez mais sendo diagnosticada nessas duas espécies (Schroeder et al. 1994, Giri et al. 2011, Uchôa et al. 2012).

A criptococose com envolvimento cerebral tem sido relatada com certa frequência em cães (Marcasso et al. 2005, Pavarini et al. 2007), porém na rotina do HV foi pouco frequente. Apesar da identificação de algumas condições imunossupressoras em cães, como administração de corticosteroides, erliquiose, dirofilariose e neoplasia, este agente pode ser um patógeno primário (Lappin 2015), entretanto não foi possível estabelecer fator imunossupressor neste caso. As lesões vasculares disseminadas verificadas nesse caso podem ter contribuído no desencadeamento da doença, entretanto não foi possível estabelecer sua causa.

A mucormicose, observada em um caso, refere-se ao conjunto de micoses oportunistas causadas por fungos potencialmente angioinvasivos, das quais estão incluídas algumas espécies dos gêneros Absidia spp., Rhizopus spp. e Mucor spp. (Ribes et al. 2000). Em cães há apenas relato da forma nasal da doença (Shirani et al. 2008). Embora existam registros dessa enfermidade nos animais domésticos, a ocorrência é considerada extremamente rara (Shirani et al. 2008), e o comprometimento do SNC é relatado por extensão em bovino (Vasconcelos \& Grahn 1995) e no homem (Costa et al. 2011).

Candida sp. é um agente oportunista, geralmente descrita em cães imunossuprimidos (Pressler 2012), já tendo relatos de associação com o parvovírus em filhote (Rodríguez et al. 1998) e a utilização prolongada de corticosteroide (Hesetine et al. 2003), mas também descrito em imunocompetentes (Brown et al. 2005). Neste caso o provável fator imunossupressor foi a co-infecção com o VCC.

Neste estudo, os traumatismos representaram a segunda maior causa de alterações neurológicas, acometendo principalmente cães errantes. Esses casos estiveram associados predominantemente a atropelamentos por veículos automotivos, semelhante ao reportado por Trapp et al. (2010), estando ainda entre as três causas principais de morte em cães no Brasil (Bentubo et al. 2007, Fighera et al. 2008b). Os traumas ocorreram com maior frequência na medula espinhal, semelhante ao reportado por Fighera et al. (2008a), que sugere que essa alta prevalência em decorrência do impacto do veículo no corpo dos cães.

Os neoplasmas, terceira causa mais importante deste estudo, também demonstrou ser uma significativa causa de disfunção neurológica, afetando principalmente cães de meia idade e idosos, semelhante ao relatado por outros autores (Santos et al. 2012). Em alguns países como Japão (Inoue et al. 2015), Estados Unidos (Bonnett et al. 2005, Fleming et al. 2011) e Dinamarca (Proschowsky et al. 2003) os neoplasmas são as principais causas de morte em cães. No Brasil, essa prevalência é mais baixa provavelmente pela alta frequência de doenças infecciosas e menor expectativa de vida dos cães (Bentubo et al. 2007, Fighera et al. 2008b, Trapp et al. 2010), também demonstrado em nosso trabalho.

Em nosso estudo os neoplasmas metastáticos foram mais frequentes, semelhante ao estudo Snyder et al. (2008). LeCouteur \& Withrow (2007) relatam que as neoplasias cerebrais ocorrem em cães de todas as idades e todas as raças, sendo mais frequentes em cães mais velhos. Snyder et al. (2006) e Santos et al. (2012) relataram que os cães da raça Boxer estão entre os mais acometidos por neoplasmas do SNC. A maior ocorrência neste estudo de neoplasias em cães sem raça definida deve estar relacionada à população canina atendida no HV/UFCG.

Dentre as neoplasias secundárias, a mais comum foi o linfoma, semelhante ao reportado por Rossmeisl \& Pancotto (2012). Chama atenção também a forma encefálica do TVT, como a segunda causa mais frequente de neoplasias metastáticas. Apesar da instituição de tratamento, alguns casos podem apresentar resistência à quimioterapia com sulfato de vincristina, associados a condições de desnutrição e/ou imunossupressão (Fernandes et al. 2013).

Os distúrbios metabólicos que podem desencadear alterações neurológicas foram pouco frequentes e estavam relacionados à insuficiência hepática e renal. Neste estudo, os distúrbios clínicos neurológicos de encefalopatia hepática foram atribuídos à insuficiência hepática crônica em decorrência de cirrose e tumores hepáticos associados com desvio vascular (shunt) adquirido. Foram observadas alterações astrocitárias, neuronais e vasogênicas. Essas disfunções ocorrem principalmente em função da hiperamonemia (Häussinger \& Schliess 2008, Zachary 2013). A alteração espongiosa que pode estar 
presente em alguns casos de encefalopatia hepática (Zachary 2013), nesse estudo esteve ausente. Os casos de encefalopatia urêmica estiveram relacionados à insuficiência renal aguda ou crônica em decorrência de lesões intersticiais, tubulares e glomerulares. Entretanto, na maioria dos casos não foram visualizadas lesões morfológicas no SNC, exceto em um caso que havia arterite fibrinoide. Alterações morfológicas e/ou estruturais no SNC em decorrência de lesões extrarrenais de uremia comumente não são descritas (Silveira et al. 2015).

A hidrocefalia está entre as malformações congênitas e anomalias do desenvolvimento mais comuns na Medicina Veterinária (Zachary 2013) e foi a única observada neste estudo. Na maioria dos casos aqui observados havia alteração morfológica do crânio. Nos casos que não houve dilatação do crânio provavelmente a distensão dos espaços ventriculares por líquor ocorreu após o fechamento das suturas cranianas (Thomas 1999, Zachary 2013). Apesar de ter ocorrido predominantemente em cães SRD, pôde-se observar também em cães de raças braquicefálicas, que são clinicamente as raças mais frequentemente afetadas (Zachary 2013).

As doenças cerebrovasculares, que incluem infartos isquêmicos e hemorrágicos, apresentaram baixa frequência, semelhante ao reportado por Wessmann et al. (2009) que admitiram uma frequência de $2 \%$ dos casos de alterações neurológicas. Estas doenças referem-se a qualquer anormalidade cerebral resultante de um processo patológico no sistema circulatório sanguíneo e estão incluídas trombose, embolismo ou hemorragia (Victor \& Ropper 2001, Kalimo et al. 2002).

Os infartos isquêmicos são cada vez mais reconhecidos como uma causa de déficits neurológicos agudos em cães (Thomsen et al. 2016) e foram os mais frequentes nesse estudo, semelhante ao reportado Joseph et al. (1988). Thomsen et al. (2016) reportaram o cerebelo como local comum para ocorrência de acidente vascular cerebral isquêmico, porém neste estudo o local mais comum para infarto isquêmico foi a região de ponte do tronco encefálico. Já os infartos hemorrágicos ocorreram predominantemente no córtex cerebral.

Além das causas aqui reportadas, como tromboembolismo séptico associado à endocardite valvar e semilunar, êmbolo neoplásico de carcinoma mamário, septicemia, outros relatos de infartos cerebrais em cães incluem êmbolos de neoplasias primárias do tecido nervoso, êmbolos metastáticos de carcinoma neuroendócrino e carcinoma prostático (Joseph et al. 1988, Kent et al. 2001), êmbolos parasitários (Kotani et al. 1975), fibrocartilaginosos (Axlund et al. 2004) e de gordura (Müller et al. 1994). Além de aterosclerose associada com hipotireoidismo, hiperadrenocorticismo, hiperliproteinemia ou hipercolesterolemima hereditária (Patterson et al. 1985, Liu et al. 1986, Joseph et al. 1988, Hess et al. 2003). Outra causa tem sido atribuída hipertensão mais comumente associada à doença renal crônica e hiperadrenocorticismo (Garosi 2010). Casos de hemorragias cerebrais secundárias têm sido associados ainda à doença vascular congênita, vasculite necrosante, deficiência na coagulação e infecção por Angiostrongylus vasorum (Garosi et al. 2005a, 2005b). Entretanto, nem sempre uma causa subjacente é identificada para doença cerebrovascular, como ocorreu em um caso.

Casos de vasculite em cães são relatados com pouca frequência, e na literatura há poucas síndromes definidas na Medicina Veterinária que podem ser referidas como vasculites primárias ou secundárias (Tipold \& Schatzberg
2010, Swann et al. 2015). Entretanto em nosso estudo não foi possível identificar a causa em nenhum dos casos.

A DDIV foi pouco frequente neste estudo, semelhante ao observado por Fighera et al. (2008b) que representou 0,9\% das causas de morte de cães. Apesar de cães condrodistróficos serem mais susceptíveis a apresentar alterações biomecânicas da coluna (Dewey 2014), os dois casos aqui observados ocorreram em cães de raça não condrodistrófica, mas que apresentam predisposição a lesões Hansen Tipo II (Marinho et al. 2014).

Alterações inflamatórias não infecciosas, como MEG e granuloma de colesterol foram incomuns neste estudo. No caso de MEG tratava-se de alterações com envolvimento predominantemente vascular, de caráter reticuloproliferativo e a predileção pela substância branca do tecido nervoso, semelhante ao reportado por Bandarra et al. (1995). A etiologia dessa condição inflamatória ainda permanece desconhecida e ocorre predominantemente em cães adultos jovens de raças pequenas, sendo os Poodles, raças do tipo toy e Terriers mais comumente afetados (O'Neill et al. 2005, Granger et al. 2010).

0 granuloma de colesterol intracerebral, encontrado em um caso, é pouco frequente em cães e tem sido relatado no cérebro (Steiss et al. 1990) e no quarto ventrículo (Lovett et al. 2012). Esta condição é frequentemente relatada em cavalos velhos como um achado incidental post mortem, porém alguns casos podem resultar em hidrocefalia secundária (Jackson et al. 1994), resultante de edema e hemorragia constante dentro do plexo com deposição de colesterol, induzindo reação inflamatória do tipo corpo estranho (Zachary 2013). Granulomas de colesterol intracranianos também têm sido relatados em gatos adultos jovens associados à hipercolesterolemia (Ricci et al. 2010) e em gatos velhos sem causa aparente (Fluehmann et al. 2006), como nesse caso, em que não foi possível identificar uma causa.

\section{CONCLUSÕES}

As doenças do sistema nervoso central, sejam primárias ou secundárias, ocorrem comumente e são responsáveis pela morte ou motivo para eutanásia em cães encaminhados para o Hospital Veterinário da UFCG, Patos, Paraíba.

As doenças infecciosas, os traumas e as neoplasias foram as mais frequentemente diagnosticadas. Dentre as infecciosas, a cinomose foi a principal causa de morte e ainda responsável pelo desencadeamento de infecções bacterianas, parasitárias e fúngicas.

Para auxiliar clínicos e patologistas nos principais diagnósticos diferenciais relacionados aos sinais neurológicos presentes, alguns dados devem ser considerados, como a idade, a espécie, a raça, localização e evolução dos sinais clínicos.

\section{REFERÊNCIAS}

Abramo F., Bastelli F., Nardoni S. \& Mancianti F. 2002. Feline cutaneuos phaeohyphomycosis due to Cladophyalophora bantiana. J. Feline Med. Surg. 4(3):157-163. http://dx.doi.org/10.1053/jfms.2002.0183. PMid:12360955.

Axlund T.W., Isaacs A.M., Holland M. \& O’Brien D.P. 2004. Fibrocartilaginous embolic encephalomyelopathy of the brainstem and midcervical spinal cord in a dog. J. Vet. Intern. Med. 18(5):765-767. http://dx.doi. org/10.1111/j.1939-1676.2004.tb02620.x. PMid:15515599.

Bandarra E.P., Laufer R., Sequeira J.L., Schamall R.F., Figueiredo L.M.A. \& Castro M.B. 1995. Meningoencefalite granulomatosa em cão. Braz. J. Vet. Res. Anim. Sci. 32(2):101-104. http://dx.doi.org/10.11606/issn.16784456.bjvras.1994.52095. 
Bauer R.W., Harrison L.R., Watson C.W., Styer E.L. \& Chapman Junior W.L. 1993. Isolation of Acanthamoeba sp. from a greyhound with pneumonia and granulomatous amebic encephalitis. J. Vet. Diagn. Invest. 5(3):386391. http://dx.doi.org/10.1177/104063879300500314. PMid:8373852.

Bentubo H.D.L., Tomaz M.A., Bondan E.F. \& Lallo M.A. 2007. Expectativa de vida e causas de morte em cães na área metropolitana de São Paulo, Brasil. Ciência Rural 37(4):1021-1026. http://dx.doi.org/10.1590/S010384782007000400016

Bonnett B.N., Egenvall A., Hedhammar A. \& Olson P. 2005. Mortality in over 350,000 insured Swedish dogs from 1995-2000: I, breed, gender, age and cause-specific rates. Acta Vet. Scand. 46(3):105-120. http://dx.doi. org/10.1186/1751-0147-46-105. PMid:16261924.

Brown M.R., Thompson C.A. \& Mohamed F.M. 2005. Systemic candidiasis in an apparently immunocompetent dog. J. Vet. Diagn. Invest. 17(3):272-276. http://dx.doi.org/10.1177/104063870501700312. PMid:15945387.

Caudell D., Confer R.W., Fulton A., Berry J.T., Saliki G.M., Fent J.W. \& Ritchey J.W. 2005. Diagnosis of infectious canine hepatitis virus (CAV-1) infection in puppies with encephalopathy. J. Vet. Diagn. Invest. 17(1):58-61. http:// dx.doi.org/10.1177/104063870501700111. PMid:15690952.

Chaves R.O., Beckmann D.V., Santos R.P., Aiello G., Andrades A.O., Baumhardt R., Silveira L.B. \& Mazzanti A. 2014. Doenças neurológicas em cães atendidos no Hospital Veterinário da Universidade Federal de Santa Maria, RS: 1.184 casos (2006-2013). Pesq. Vet. Bras. 34(10):996-1001. http://dx.doi. org/10.1590/S0100-736X2014001000012.

Costa M.A., Reis R.F., Seca M., Queirós J., Pinto M.C. \& Araújo M. 2011. Mucormicose rino-cerebral: caso clínico e revisão de literatura. Oftalmologia 35(4):355-359.

Craig L.E. 2001. Cause of death in dogs according to breed: a necropsy survey of five breeds. J. Am. Anim. Hosp. Assoc. 37(5):438-443. http://dx.doi. org/10.5326/15473317-37-5-438. PMid:11563442.

Daft B.M., Visvesvara G.S., Read D.H., Kinde H., Uzal F.A. \& Manzer M.D. 2005. Seasonal meningoencephalitis in Holstein cattle caused by Naegleria fowleri. J. Vet. Diagn. Invest. 17(6):605-609. http://dx.doi. org/10.1177/104063870501700617. PMid:16475525.

Dewey C.W. 2014. Cirurgia da coluna cervical, p.1467-1502. In: Fossum T.W. (Ed), Cirurgia de Pequenos Animais. 4⿳⺈ ed. Elsevier, Rio de Janeiro. (Tradução)

Dubey J.P., Benson J.E., Blakeley K.T., Booton G.C. \& Visvesvara G.S. 2005 Disseminated Acanthamoeba sp. infection in a dog. Vet. Parasitol. 128(3/4):183187. http://dx.doi.org/10.1016/j.vetpar.2004.11.022. PMid:15740854.

Fawi M.T., Tag El Din M.T. \& El-Sanousi S.M. 1971. Canine distemper as a predisposing factor for Nocardia asteroides infection in the dog. Vet. Rec. 88(13):326-328. http://dx.doi.org/10.1136/vr.88.13.326. PMid:5103436.

Fernandes C.P.M., Gaspar L.F.J., Meinerz A.R.M., Grecco F.B., Nobre M.O. \& Cleff M.B. 2013. Tumor venéreo transmissível canino com metástase encefálica. Semina, Ciênc. Agrárias 34(6):3929-3934. http://dx.doi. org/10.5433/1679-0359.2013v34n6Supl2p3929.

Fighera R.A., Silva M.C., Souza T.M., Brum J.S., Kommers G.D., Graça D.L., Irigoyen L.F. \& Barros C.S.L. 2008a. Aspectos patológicos de 155 casos fatais de cães atropelados por veículos automotivos. Ciência Rural 38(5):1375-1380. http://dx.doi.org/10.1590/S0103-84782008000500028.

Fighera R.A., Souza T.M., Silva M.C., Brum J.S., Graça D.L., Kommers G.D., Irigoyen L.F. \& Barros C.S.L. 2008b. Causas de morte e razões para eutanásia de cães da Mesorregião do Centro Ocidental Rio-Grandense (1965-2004). Pesq. Vet. Bras. 28(4):223-230. http://dx.doi.org/10.1590/ S0100-736X2008000400005.

Fleming J.M., Creevy K.E. \& Promislow D.E. 2011. Mortality in north american dogs from 1984 to 2004: an investigation into age, size, and breed related causes of death. J. Vet. Intern. Med. 25(2):187-198. http://dx.doi. org/10.1111/j.1939-1676.2011.0695.x. PMid:21352376.

Fluehmann G., Doherr M.G. \& Jaggy A. 2006. Canine neurological diseases in a referral hospital population between 1989 and 2000 in Switzerland.
J. Small Anim. Pract. 47(10):582-587. http://dx.doi.org/10.1111/j.17485827.2006.00106.x. PMid:17004950.

Foreman 0., Sykes J., Ball L., Yang N. \& De Cock H. 2004. Disseminated infection with Balamuthia mandrillaris in a dog. Vet. Pathol. 41(5):506-510. http:// dx.doi.org/10.1354/vp.41-5-506. PMid:15347823.

Frade M.T.S. 2014. Amebíase sistêmica e toxoplasmose associadas à cinomose em cães no semiárido da Paraíba. Dissertação de Mestrado, Centro de Saúde e Tecnologia Rural, Universidade Federal de Campina Grande. 54p.

Frade M.T.S., Melo L.F., Pessoa C.R.M., Araújo J.L., Fighera R.A., Souza A.P., Uzal F. \& Dantas A.F.M. 2015a. Systemic acanthamoebiasis associated with canine distemper in dogs in the semiarid region of Paraíba, Brazil. Pesq. Vet. Bras. 35(2):160-164. http://dx.doi.org/10.1590/S0100-736X2015000200011.

Frade M.T.S., Maia L.A., Andrade R.L.F.S., Alves R.C., Yamasaki E.M., Mota R.A. \& Dantas A.F.M. 2015b. Clinical, pathological, and immunohistochemistry characterization of toxoplasmosis in dogs with distemper in the semiarid region of Paraíba, Brazil. Semina, Ciênc. Agrárias 36(6):4251-4256. http:// dx.doi.org/10.5433/1679-0359.2015v36n6Supl2p4251.

Garosi L.S. 2010. Cerebrovascular disease in dogs and cats. Vet. Clin. N. Am., Small Anim. Pract. 40(1):65-79. http://dx.doi.org/10.1016/j. cvsm.2009.09.001. PMid:19942057.

Garosi L., McConnell J.E., Platt S.R., Barone G., Baron J.C., DeLahunta A. \& Schatzberg S.J. 2005a. Results of diagnostic investigations and long-term outcome of 33 dogs with brain infarction (2000-2004). J. Vet. Intern. Med. 19(5):725-731. PMid:16231718.

Garosi L.S., Platt S.R., McConnell J.F., Wray J.D. \& Smith K.C. 2005b. Intracranial haemorrhage associated with Angiostrongylus vasorum infection in three dogs. J. Small Anim. Pract. 46(2):93-99. http://dx.doi. org/10.1111/j.1748-5827.2005.tb00300.x. PMid:15736817.

Giri D.K., Sims W.P., Sura R., Cooper J.J., Gavrilov B.K. \& Mansell J. 2011. Cerebral and renal phaeohyphomycosis in a dog with infected Bipolaris species. Vet. Pathol. 48(3):754-757. http://dx.doi.org/10.1177/0300985810375239. PMid:20574070.

Granger N., Smith P.M. \& Jeffery N.D. 2010. Clinical findings and treatment of non-infectious meningoencephalomyelitis in dogs: a systematic review of 457 published cases from 1962 to 2008. Vet. J. 184(3):290-297. http:// dx.doi.org/10.1016/j.tvjl.2009.03.031. PMid:19410487.

Greene C.E. 2012. Infectious canine hepatitis and canine acidophil cell hepatitis, p.42-47. In: Greene C.E. (Ed), Infectious Disease of the Dog and Cat. 4th ed. Saunders Elsevier, St Louis.

Häussinger D. \& Schliess F. 2008. Pathogenetic mechanisms of hepatic encephalopathy. Gut 57(8):1156-1165. http://dx.doi.org/10.1136/ gut.2007.122176. PMid:18628377.

Headley S.A. \& Graça D.L. 2000. Canine distemper: epidemiological findings of 250 cases. Braz. J. Vet. Res. Anim. Sci. 37(2):136-140. http://dx.doi. org/10.1590/S1413-95962000000200009.

Herráez P., Rees C. \& Dunstan R. 2001. Invasive phaeohyphomycosis caused by Curvularia Species in a dog. Vet. Pathol. 38(4):456-459. http://dx.doi. org/10.1354/vp.38-4-456. PMid:11467482.

Hesetine J.C., Panciera D.L. \& Saunders G.K. 2003. Systemic candidiasis in a dog. J. Am. Vet. Med. Assoc. 223(6):821-824, 810. http://dx.doi.org/10.2460/ javma.2003.223.821. PMid:14507099.

Hess R.S., Kass P.H. \& Winkle T.J. 2003. Association between diabetes mellitus, hypothyroidism or hyperadrenocorticism, and atherosclerosis in dogs. J. Vet. Intern. Med. 17(4):489-494. http://dx.doi.org/10.1111/j.1939-1676.2003. tb02469.x. PMid:12892299.

Inkelmann M.A., Rozza D.B., Fighera R.A., Kommers G.D., Graça D.L., Irigoyen L.F. \& Barros C.S.L. 2007. Hepatite infecciosa canina: 62 casos. Pesq. Vet. Bras. 27(8):325-332. http://dx.doi.org/10.1590/S0100-736X2007000800002. 
Inoue M., Hasegawa A., Hosoi Y. \& Sugiura K. 2015. A current life table and causes of death for insured dogs in Japan. Prev. Vet. Med. 120(2):210-218. http://dx.doi.org/10.1016/j.prevetmed.2015.03.018. PMid:25896026.

Jackson C.A., DeLahunta A., Dykes N.L. \& Divers T.J. 1994. Neurological manifestation of cholesterinic granulomas in three horses. Vet. Rec. 135(10):228-230. http://dx.doi.org/10.1136/vr.135.10.228. PMid:7801440.

Joseph R.J., Greenlee M.S., Carrillo J.M. \& Kay W.J. 1988. Canine cerebrovascular disease: clinical and pathological findings in 17 cases. J. Am. Anim. Hosp. Assoc. 24:569-576.

Kalimo H., Kaste M. \& Haltia M. 2002. Vascular diseases, p.281-355. In: Graham D.I. \& Lantos P.L. (Eds), Greenfield's Neuropathology. Vol.1. Arnold, London.

Kent M., DeLahunta A. \& Tidwell A.S. 2001. MR imaging findings in a dog with intravascular lymphoma in the brain. Vet. Radiol. Ultrasound 42(6):504-510. http://dx.doi.org/10.1111/j.1740-8261.2001.tb00977.x. PMid:11768516.

Kent M., Platt S.R., Rech R.R., Eagleson J.S., Howerth E.W., Shoff M., Fuerst P.A., Booton G., Visvesvara G.S. \& Schatzberg S.J. 2011. Multisystemic infection with an Acanthamoeba sp in a dog. J. Am. Vet. Med. Assoc. 238(11):14761481. http://dx.doi.org/10.2460/javma.238.11.1476. PMid:21627512.

Kotani T., Tomimura T., Ogura M., Yoshida H., Mochizuki H. \& Koreeda T. 1975. Cerebral infarction caused by Dirofilaria immitis in three dogs. Nippon Juigaku Zasshi 37(4):379-390. http://dx.doi.org/10.1292/ jvms1939.37.379. PMid:1238861.

Lappin M.R. 2015. Doenças infecciosas, p.1283-1397. In: Nelson R.W \& Couto C.G. (Eds), Medicina Interna de Pequenos Animais. 5a ed. Mosby Elsevier, Rio de Janeiro.

LeCouteur R.A. \& Withrow S.J. 2007. Tumors of the nervous system, p.659685. In: Withrow S.J. \& Vail D.M. Withrow (Eds), MacEwen's Small Animal Clinical Oncology. $4^{\text {th }}$ ed. Saunders Elsevier, St Louis.

Liu S.K., Tilley L.P., Tappe J.P. \& Fox P.R. 1986. Clinical and pathologic findings in dogs with atherosclerosis: 21 cases (1970-1983). J. Am. Vet. Med. Assoc. 189(2):227-232. PMid:3744984.

Lovett M.C., Fenner W.R., Watson A.T. \& Hostutler R.A. 2012. Imaging diagnosis, MRI characteristics of a fourth ventricular cholesterol granuloma in a dog. Vet. Radiol. Ultrasound 53(6):650-654. http://dx.doi.org/10.1111/j.17408261.2012.01946.x. PMid:22731914.

Marcasso R.A., Sierra S., Arias M.V.B., Bracarense A.P.F.R.L., Yamamura A.A.M., Biasi F., Lopes B.A., Amude A.M. \& Cortêz D.E.A. 2005. Criptococose no sistema nervoso de cães: relato de três casos. Semina, Ciênc. Agrárias 26(2):229-238. http://dx.doi.org/10.5433/1679-0359.2005v26n2p229.

Marinho P.V.T., Arias M.V.B., Zani C.C. \& Minto B.W. 2014. Doença do disco intervertebral Hansen tipo II em cães: fisiopatologia, abordagem clínicocirúrgica e controvérsias. Semina, Ciênc. Agrárias 35(3):1395-1414. http:// dx.doi.org/10.5433/1679-0359.2014v35n3p1395.

Martinez A.J. \& Visvesvara G.S. 1997. Free-living, amphizoic and opportunistic amebas. Brain Pathol.7(1):583-598. http://dx.doi.org/10.1111/j.1750-3639.1997. tb01076.x. PMid:9034567.

McKenzie R.A., Connole M.D., McGinnis M.R. \& Lepelaar R. 1984. Subcutaneous phaeohyphomycosis caused by Moniliella suaveolens in two cats. Vet. Pathol. 21(6):582-586. http://dx.doi.org/10.1177/030098588402100606. PMid:6542716.

Müller C., Rahn B.A., Pfister U. \& Meinig R.P. 1994. The incidence, pathogenesis, diagnosis, and treatment of fat embolism. Orthop. Rev. 23(2):107-117. PMid:8196970.

O'Neill E.J., Merrett D. \& Jones B. 2005. Granulomatous meningoencephalomyelitis in dogs: a review. Irish Vet. J. 58(2):86-92. http://dx.doi.org/10.1186/20460481-58-2-86. PMid:21851667.

Patterson J.S., Rusley M.S. \& Zachary J.F. 1985. Neurologic manifestations of cerebrovascular atherosclerosis associated with primary hypothyroidism in a dog. J. Am. Vet. Med. Assoc. 186(5):499-503. PMid:3972713.
Pavarini S.P., Bezerra Júnior P.S., Santos A.S., Sonne L., Oliveira E.C. \& Driemeier D. 2007. Leptomeningite e hidrocefalia causadas por Cryptococcus sp. em um cão. Acta Scient. Vet. 35(3):389-392.

Pimentel L.A., Dantas A.F.M., Uzal F. \& Riet-Correa F. 2012. Meningoencephalitis caused by Naegleria fowleri in cattle of northeast Brazil. Res. Vet. Sci. 93(2):811-812.http://dx.doi.org/10.1016/j.rvsc.2012.01.002. PMid:22285703.

Poutahidis T., Angelopoulou K., Karamanavi E., Polizopoulou Z.S., Doulberis M., Latsari M. \& Kaldrymidou E. 2009. Mycotic encephalitis and nephritis in a dog due to infection with Cladosporium cladosporioides. J. Comp. Pathol. 140(1):59-63. http://dx.doi.org/10.1016/j.jcpa.2008.09.002. PMid:19064269.

Pressler B.M. 2012. Candidiasis and rhodotorulosis, p.666-672. In: Greene C.E. (Ed.), Infectious Diseases of the Dog and Cat. 4th ed. Saunders Elsevier, St Louis.

Proschowsky H.F., Rugbjerg H. \& Ersboll A.K. 2003. Mortality of purebreed and mixed-breed dogs in Denmark. Prev. Vet. Med. 58(1/2):63-74. http:// dx.doi.org/10.1016/S0167-5877(03)00010-2. PMid:12628771.

Reed L.T., Miller M.A., Visvesvara G.S., Gardiner C.H., Logan M.A. \& Packer R.A. 2010. Diagnostic exercise: cerebral mass in puppy with respiratory distress and progressive neurologic signs. Vet. Pathol. 47(6):1116-1119. http://dx.doi.org/10.1177/0300985810374835. PMid:20634413.

Ribeiro M.G. \& Condas L.A. 2016. Enfermidades pelo gênero Nocardia, p.199211. In: Megid J., Ribeiro M.G. \& Paes A.C. (Eds), Doenças Infecciosas em Animais de Produção e de Companhia. Roca, Rio de Janeiro.

Ribes J.A., Vanover-Sams C.L. \& Baker D.J. 2000. Zigomycets in human disease. Clin. Microbiol. Rev. 13(2):236-301. http://dx.doi.org/10.1128/ CMR.13.2.236-301.2000. PMid:10756000.

Ricci E., Abbiati G. \& Cantile C. 2010. Intracranial cholesterol granuloma in a cat. J. Vet. Med. Sci. 72(11):1475-1478. http://dx.doi.org/10.1292/ jvms.10-0153. PMid:20543528.

Rodríguez F., Fernandez A., Espinosa de los Monteros A., Wohlsein P. \& Jensen H.E. 1998. Acute disseminated candidiasis in a puppy associated with parvoviral infection. Vet. Rec. 142(16):434-436. http://dx.doi.org/10.1136/ vr.142.16.434. PMid:9595635.

Rossmeisl J. \& Pancotto T. 2012. Intracranial neoplasia and secondary pathological effects, p.461-478. In: Platt S. \& Garosi L. (Eds), Small Animal Neurological Emergencies. Manson, London. http://dx.doi.org/10.1201/ b15214-30.

Santini G., Mazzanti A., Beckmann D.V., Santos R.P., Pelizzari C., Polidoro D. \& Baumhardt R. 2010. Doença do disco intervertebral cervical em cães: 28 casos (2003-2008). Pesq. Vet. Bras. 30(8):659-664. http://dx.doi. org/10.1590/S0100-736X2010000800009.

Santos R.P., Fighera R.A., Beckmann D.V., Brum J.S., Ripplinger A., P. Neto D., Baumhardt R. \& Mazzanti A. 2012. Neoplasmas envolvendo o sistema nervoso central de cães: 26 casos (2003-2011). Pesq. Vet. Bras. 32(2):153158. http://dx.doi.org/10.1590/S0100-736X2012000200011.

Schroeder H., Jardine J.E. \& Davis V. 1994. Systemic phaeohyphomycosis caused by Xylohypha bantiana in a dog. J. S. Afr. Vet. Assoc. 65(4):175-178. PMid:7602573.

Shirani D., Ghaffari M.S., Khosravi A.R., Vajhi A.R., Khorami N., Salehi T.Z., Shokri H. \& Abarkar M. 2008. An unusual case of nasal mucormycosis caused by Rhizopus oryzae in a German Sherphed dog. Iran. J. Vet. Res. 9:378-380.

Silva M.C., Fighera R.A., Brum J.S., Graça D.L., Kommers G.D., Irigoyen L.F. \& Barros C.S.L. 2007. Aspectos clinicopatológicos de 620 casos neurológicos de cinomose em cães. Pesq. Vet. Bras. 27(5):215-220. http://dx.doi. org/10.1590/S0100-736X2007000500006.

Silveira I.P., Inkelmann M.A., Tochetto C., Rosa F.B., Fighera R.A., Irigoyen L.F. \& Kommers G.D. 2015. Epidemiologia e distribuição de lesões extrarrenais de uremia em 161 cães. Pesq. Vet. Bras. 35(6):562-568. http://dx.doi. org/10.1590/S0100-2015000600013. 
Sisk D.B. \& Chandler F.W. 1982. Phaeohyphomycosis and Cryptococcosis in a cat. Vet. Pathol. 19(5):554-556. http://dx.doi.org/10.1177/030098588201900511. PMid:7147615.

Snyder J.M., Shofer F.S., Van Winkle T.J. \& Massicotte C. 2006. Canine intracranial primary neoplasia: 173 cases (1986-2003). J. Vet. Intern. Med. 20(3):669675. PMid:16734106.

Snyder J.M., Lipitz L., Skorupski K.A., Shofer F.S. \& Van Winkle T.J. 2008. Secondary intracranial neoplasia in the dog: 177 cases (1986-2003). J. Vet. Intern. Med. 22(1):172-177. http://dx.doi.org/10.1111/j.19391676.2007.0002.x. PMid:18289306.

Sonne L., Oliveira E.C., Pescador C.A., Santos A.S., Pavarini S.P., Carissimi A.S. \& Driemeier D. 2009. Achados patológicos e imuno-histoquímicos em cães infectados naturalmente pelo vírus da cinomose canina. Pesq. Vet. Bras. 29(2):143-149. http://dx.doi.org/10.1590/S0100-736X2009000200010.

Steiss J.E., Cox N.R. \& Knecht C.D. 1990. Electroencephalographic and histopathologic correlations in eight dogs with intracranial mass lesions. Am. J. Vet. Res. 51(8):1286-1291. PMid:2386329.

Swann J.W., Priestnall S.L., Dawson C., Chang Y. \& Garden O.A. 2015. Histologic and clinical features of primary and secondary vasculitis: a retrospective study of 42 dogs (2004-2011). J. Vet. Diagn. Invest. 27(4):489-496. http:// dx.doi.org/10.1177/1040638715587934. PMid:26077546.

Thomas W.B. 1999. Nonneoplastic disorders of the brain. Clin. Tech. Small Anim. Pract. 14(3):125-147. http://dx.doi.org/10.1016/S1096-2867(99)800309. PMid:10457657.

Thomsen B., Garosi L., Skerritt G., Rusbridge C., Sparrow T., Berendt M. \& Gredal H. 2016. Neurological signs in 23 dogs with suspected rostral cerebellar ischaemic stroke. Acta Vet. Scand. 58(1):1-9. PMid:27267355.
Tipold A. \& Schatzberg S.J. 2010. An update on steroid responsive meningitisarteritis. J. Small Anim. Pract. 51(3):150-154. http://dx.doi.org/10.1111/ j.1748-5827.2009.00848.x. PMid:20070497.

Tizard I.R. 2014. Uso de vacinas, p.272-282. In: Tizard I.R. (Ed), Imunologia Veterinária. 9a ed. Elsevier, Rio de Janeiro. (Tradução)

Trapp S.M., Iacuzio A.I., Barca Junior F.A., Kemper B., Silva L.C., Okano W., Tanaka N.M., Grecco F.C.A.R., Cunha Filho L.F.C. \& Sterza F.A.M. 2010. Causas de óbito e razões para eutanásia em uma população hospitalar de cães e gatos. Braz. J. Vet. Res. Anim. Sci. 47(5):395-402. http://dx.doi. org/10.11606/issn.1678-4456.bjvras.2010.26821.

Uchôa I.C.P., Santos J.R.S., Souza A.P., Dantas A.F.M., Borges O.M.M. \& Medeiros L.C. 2012. Feo-hifomicose sistêmica em cão. Ciência Rural 42(4):670-674. http://dx.doi.org/10.1590/S0103-84782012000400015.

Vasconcelos D.Y. \& Grahn B.H. 1995. Disseminated rhizopus infection with ocular involvement in a calf. Vet. Pathol. 32(1):78-81. http://dx.doi. org/10.1177/030098589503200115. PMid:7725604.

Victor M. \& Ropper A.H. 2001. Cerebrovascular diseases, p.821-924. In: Wonsiewicz M.J., Medina M.P. \& Navrozov M. (Eds), Adams and Victor's Principles of Neurology. McGraw-Hill, New York.

Wessmann A., Chandler K. \& Garosi L. 2009. Ischaemic and haemorrhagic stroke in the dog. Vet. J. 180(3):290-303. http://dx.doi.org/10.1016/j. tvjl.2007.12.023. PMid:18579421.

Wigton D.H., Kociba G.J. \& Hoover E.A. 1976. Infectious canine hepatitis: animal model for viral-induced disseminated intravascular coagulation. Blood 47(2):287-296. PMid:1244923.

Zachary J.F. 2013. Sistema nervoso, p.774-873. In: McGavin M.D. \& Zachary J.F. (Eds), Bases da Patologia em Veterinária. 5aa ed. Mosby Elsevier, Rio de Janeiro. (Tradução) 